\title{
Research on the Construction of Hunan Changwei Logistics Park
}

\author{
Shijun Yuan \\ Hunan Modern Logistics College \\ Changsha, China 410131
}

\author{
Zhengxin $\mathrm{Wu}$ \\ Hunan Modern Logistics College \\ Changsha, China 410131
}

\author{
Jianhua Chen* \\ Hunan Modern Logistics College \\ Changsha, China 410131 \\ *Corresponding Author
}

\begin{abstract}
Based on the in-depth analysis of the background and significance of the construction of Hunan Changwei Logistics Park, this paper forecasts its logistics needs and construction scale, and proposes the main construction contents and planning requirements.
\end{abstract}

Keywords-logistics park; construction; research

\section{INTRODUCTION}

Hunan Changwei Logistics Park construction project closely serves the overall economic and social development of Changsha City and Hunan Province. Relying on location and infrastructure advantages and based on "the Great Riverwest Prior Region of Changsha", it serves "the $3+5$ urban agglomerations in Hunan Province". By heavy use of IoT technology in large quantities, a logistics center with transit and urban distribution as its main functions has been planned to be put into construction. It is striving to become a logistics hub in the Central and South China region in 2020, providing reliable logistics support for regional economic restructuring and industrial development, which will offer a strong guarantee for reducing the total cost of social logistics.

\section{PROJECT CONSTRUCTION BACKGROUND}

A. The Project Construction Meets the Requirements of the Economic and Social Development Plans of all Levels of Government

Hunan Province has successively formulated the "Thirteenth Five-Year Plan for National Economic and Social Development of Hunan Province", "Revitalization Implementation Plan for Logistics Industry (2009-2011)", "Twelfth Five-Year Plan for Logistics Industry Development of Hunan Province" and "The 13th Five-Year Plan for the Development of Logistics Industry in Hunan Province". Backed by Changsha City, Xiangjiang New District and surrounding large-scale manufacturing enterprises, this project strengthens the joint development of manufacturing and logistics industry. It conforms to the general principles of economic and social development of the "multi-industry linkage and two-type development" of the provincial party committee and the provincial government, which is in accordance with the general requirements for sustained development. Integrating social idle resources and forming a logistics gathering area, this project adopts intensive land use, with modern information technology supporting highefficiency logistics operations. That fully conforms to the strategic goal of "economic and social development and resource conservation and environmental protection" of the provincial party committee and government.

At the same time, the Hunan Changwei Logistics Park Construction Project revolves around the strategic goal of "accelerating the transformation of economic development mode, accelerating the process of high-end industrialization and promoting the development of urban and rural integration" in Changsha City, adopting "high starting point planning, high standard construction and market operation". Fully drawing on the successful operation cases of logistics parks at home and abroad, considering actual development needs of Changsha City, it well combines establishing advanced warehousing management, command dispatching and monitoring systems, planning to establish a new logistics resource network supported by Internet of Things technology, scientific planning and advanced technology. The perfect combination will built this project into a demonstration project in Changsha and even the whole country.

\section{B. Changsha Manufacturing Industry Expects Strong Support from the Modern Logistics Industry Park}

As a nuclear city in Hunan Province, Changsha City is a typical commercial and consumption-oriented city which has a sustained high-speed economic growth, highly favored capital, highly developed commodity circulation, and is entering a stage of rapid industrialization. As capacity expands, manufacturing companies are increasingly demanding logistics infrastructure and service levels of higher level. What's more, the deficit and backwardness of the logistics supporting system in Changsha, has to some 
extent restricted the development of supporting industries in the manufacturing industry. Only through the improving of the logistics environment and the regional industrial supporting system can this city achieve industrial integration and scale effect so that industrial development will further drive effective logistics demand and improve the logistics infrastructure, reducing costs and improving efficiency. The positive interaction between the logistics industry and the manufacturing industry can enhance regional comparative advantages and incite regional economic development and industrial upgrading.

\section{Changwei Has the Realistic Conditions for Building a Logistics Park}

This project is qualified to build the Hunan Changwei Logistics Park for having 4 conditions: it relies on the advantages of surrounding industries, with rich experience in logistics operation; it is equipped with strong financial strength, and the logistics business is flourishing; the talent reserve is sufficient and the leadership has a strong strategic vision for development.

\section{The SignificAnce of CONSTRUCTING THE PROJECT}

\section{A. The Project Construction Will Greatly Promote the Construction and Development of Xiangjiang New District}

Xiangjiang New District was approved by the State Council in 2015. According to the "General Plan for the Construction of Xiangjiang New District", it aim to reach an urbanization rate of around $80 \%$; develop in an annual average growth rate of regional GDP significantly higher than that of Hunan Province; increase the strategic emerging industries with an average annual growth rate of more than $20 \%$, becoming an important engine for economic and social development in the middle reaches of Hunan Province and the Yangtze River, an important support point for the construction of the Yangtze River Economic Belt, and a national "two-type" social construction pioneer zone. .

The "Overall Plan" proposes the construction of "two corridors", namely: the modern service industry corridor on the west bank of Xiangjiang River, focusing on the development of financial services, cultural innovation, services including trade and logistics; the 319 national strategic emerging industry corridors, focusing on the development of industrial clusters such as high-end manufacturing, new materials, electronic information and new energy. This project will become an important part of the logistics system of Xiangjiang New District.

\section{B. The Project Construction Will Be Conductive to Revitalizing State-owned Assets}

The project is located in a long-term idle railway freight yard. The use of it to build a logistics park that is urgently needed for the development of the Xiangjiang New Area not only promotes the construction and development of the Xiangjiang New District, but also revitalizes the idle stateowned assets, making it play a role in promoting economic and social development. Moreover, the project intends to adopt the BOT model, using social funds for construction, in line with current national requirements for government and state-owned enterprises to make full use of social funds for infrastructure construction.

\section{The Project Promote the Transformation and Upgrading of Commerce and Logistics in Changsha City}

With the rapid development of China's economy, the modern logistics industry has developed rapidly. Modern warehousing is an important part of modern logistics. Efficient and reasonable warehousing can speed up the flow of materials, reduce costs, and improve the efficiency of production and consumption. It can at the same time, reflect the level of urban modern logistics industry. At present, the storage facilities in Changsha City are backward, and the illegal construction warehouses are flooding the market, which poses huge potential safety hazards, and affects the normal market development and the development of modern logistics industry.

\section{THE FORECAST OF LOGISTICS DEMAND IN RADIATION AREA}

At present, the city's social transportation turnover is 47.309 billion tons, an increase of $9.6 \%$ over the previous year, of which passenger turnover increased by $10.3 \%$; cargo turnover increased by $7.4 \%$. It is preliminarily forecast that the traffic volume will be 517.85 million tons in 2020 .

On the one hand, there should be reasonable foresight in a planning, so the scale of the logistics park should not be planned too small, otherwise it will limit the sustainable development of regional logistics; on the other hand, from the perspective of the economic and logistics development needs, the planning scale cannot be too large, otherwise it will produce investment waste and idle logistics resources, which will also pose hidden dangers for future business operations.

Due to the many factors affecting the planning and construction scale of the logistics park, we start from the total logistics volume of the project radiation area to determine the overall construction scale of the logistics park.

In regional logistics planning, if there are 365 working days per year, the total scale of the construction of the logistics park is:

\section{$\mathrm{S}=\mathrm{L}$ I1I $2 \mathrm{a} / 365$}

In this formula: $\mathrm{S}$ is the total area of the logistics park construction (104 m2);

$\mathrm{L}$ is the total social logistics volume (104t) predicted for the target year of the plan;

I1 is the proportion of the third-party logistics (3PL) market in the planning target year to the total social logistics market;

$\mathrm{I} 2$ is the proportion of the third-party logistics (3PL) market occurred through the logistics park in the planning 
target year to the total social logistics market; "a" is the land use parameter $\mathrm{m} 2 / \mathrm{t}$ per unit capacity.

\section{A. Forecast of the Total Social Logistics Volume L in the Target Year of Planning}

In the logistics planning, the forecast of the total amount of logistics is represented by the cargo volume of Changsha City. The data comes from the statistical yearbook of Changsha City in recent years. The forecasting method can be the combination of quantitative analysis and qualitative analysis. It can be expected that by 2020 , the total freight volume will reach 517.85 million tons in the Changsha area radiated by the logistics park. According to the economic and industrial development of Wangcheng District in the whole area of Changsha City, it is estimated that the freight volume of Wangcheng District will account for about $15 \%$ of the total freight volume of Changsha City. The direct radiation cargo volume of this project accounts for $10 \%$ of the freight volume of Wangcheng District, meaning that in the target year of the plan, the total social logistics volume $\mathrm{L}$ is 7.77 million tons.

\section{B. The Value of the Proportional Coefficient II}

Since the emergence of third-party logistics in Europe and the United States in the late 1980s, demand has grown rapidly. Today, the logistics amount completed by 3PL has accounted for a considerable proportion of the entire logistics market. According to the survey data from the China Federation of Logistics and Purchasing, the supply of 3PL raw materials for customers will increase from the current $15 \%$ to $35 \%$ after 5 years; the sales of products from producers will increase from the current percentage slightly higher than $45 \%$ to $80 \%$ after 5 years; distributor logistics outsourcing will increase from the percentage just over $25 \%$ now to about $65 \%$ after 3 years. When the local social economy grows fast, the market maturity degree is high, and the logistics market demand is large, then I1 takes a large value; otherwise it takes a small value.

\section{The Value of the Proportional Coefficient I2}

The characteristics of modern logistics scale economy are very obvious: the more third-party logistics enterprises enter in the logistics park, the more professional is the division of labor, the more is competition in the logistics market, the lower is the logistics cost, the more efficient and higher quality of the logistics service is provided to the society, and the better scale effect of logistics operation can be made. This is one of the main reasons for the establishment of logistics parks in China and around the world. Moreover, the development of third-party logistics enterprises in logistics parks is an inevitable requirement of market competition. It also conforms to the development trend of world logistics. Therefore, it can be considered that most of the operations of various third-party logistics enterprises in the target year are completed in the logistics park. Considering that there are still a certain number of freight distribution markets and trading centers in the current and future period, some thirdparty traffic will be diverted; some small-scale logistics distribution centers that have not entered the logistics park will also take away a small amount of third party logistics. In addition, the short-circuit phenomenon of logistics will also reduce the flow of logistics entering the park, so not all thirdparty logistics will enter the logistics park. However, the diversion of logistics amount in the above aspects will not affect the main position in logistics of the logistics park in the coming years.

Based on the above analysis, the estimated value of the third-party logistics amount entering the logistics park in the planned target year accounts for the proportion of all thirdparty logistics market, the value of the proportional coefficient I2, is $40 \%-90 \%$. When the degree of local marketization is high, and the demand in the logistics market is large, then $\mathrm{I} 2$ takes a large value;

\section{The Value of the Land Use Parameter " $a$ " of the Unit Capacity}

Due to the lack of experience in China's logistics parks the construction, it is advisable to refer to the experience of the construction of foreign logistics parks.

The land use parameter a of the Tokyo Metropolitan Logistics Park in Japan is about 40-60 m2 / t. Considering that the economic development level and total amount of Chinese cities are far less than Tokyo and some cities may approach Tokyo in more than a decade. The current strength, therefore, the value of a in the planning and construction of China's logistics park should be smaller than $40 \sim 60 \mathrm{~m} 2 / \mathrm{t}$.

In addition, the construction planning of the logistics park can refer to the layout planning of the freight station of the highway hub, in the planning of which "a" usually takes $20 \sim 40 \mathrm{~m} 2 / \mathrm{t}$. Considering that the logistics park is more comprehensive and powerful than the highway hub freight yard, the value of "a" in the logistics park planning and construction is larger than $20-40 \mathrm{~m} 2 / \mathrm{t}$.

Based on the above two factors, the parameter "a" of the unit capacity in the planning of the logistics park can be 30$50 \mathrm{~m} 2 / \mathrm{t}$. If the local economy has strong influence on the surrounding area, then a takes a large value: the opposite is a small value.

In summary, considering the geographical location and economic environment of the project, taking into full consideration of the possible development trend of the local area in five years, $\mathrm{I} 1=40 \%, \mathrm{I} 2=40 \%, \mathrm{a}=40$, and the market share of the project logistics park in 2020 will be $50 \%$ of the share of the area. It can be calculated that:

$$
\mathrm{mu} S=777 \times 40 \% \times 40 \% \times 50 \% \times 40 / 365=6.81 \text { million } \mathrm{m} 2=102
$$

By 2020, the land area that logistics park will use to meet the logistics needs in the radiation area is about $102 \mathrm{mu}$.

\section{PROJECT PlanNING AND CONSTRUCTION}

According to the geographical location of the site and the overall planning of the existing warehouse building, the layout should be compact, reasonable, efficient, and safe, and the land utilization rate should be improved. 
This time, a total of 6 warehouses for storing C-type materials in the two-story warehouse were planned, with one original one-story warehouse for Class $\mathrm{C}$ materials and one second-story office building reserved. Auxiliary utilities such as distribution, ventilation, and construction units of fire control required in the reservoir area are provided in the first floor of each warehouse.

The newly planned logistics warehouses in the reservoir area are all two-story buildings. The building fire protection category is Class $\mathrm{C}$, using two standard span modes (8X10 meters, 8 X12 meters).

Each logistics warehouse has its own independent logistics loading and unloading yards as well as entrances and exits to meet the needs of flexible distribution in the later period.

\section{CONCLUSION}

The project is based on the requirements of modernization of facilities, intelligent hardware, and management informationization, to build a logistics park integrating the function of transportation and distribution, modern warehousing, cargo distribution, multi-modal transportation, packaging and processing, logistics information, container business, and exhibition and sales. The construction of its construction project can solve the problem of relatively backward regional logistics facilities, so its construction is necessary.

\section{REFERENCES}

[1] Zhao Gangxi. Analysis of Demand Forecast and Scale Design of HD Logistics Park [J]. Business. 2016(28)

[2] Jin Fangfang. Empirical Research on the Role of Logistics Industry Development in Economic Growth [J]. Inquiry Into Economic Issues. 2012(03)

[3] Li Ping. Research on Logistics Demand Forecasting in Logistics Park Planning $[\mathrm{J}]$. Entrepreneur World second semimonthly(Theoretical Edition). 2007(11) 